\title{
Developmental Changes in the Perception of Visuotactile Simultaneity
}

\begin{abstract}
A simultaneity judgment (SJ) task was used to measure the developmental trajectory of visuotactile simultaneity perception in children (aged 7, 9, 11, and 13 years) and adults. Participants were presented with a visual flash in the center of a computer monitor and a tap on their right index finger (located $20^{\circ}$ below the flash) with 13 possible stimulus onset asynchronies (SOAs). Participants reported whether the flash and tap were presented at the same time. Compared to the adult group, children aged 7 and 9 years made more simultaneous responses when the tap led by more than $300 \mathrm{~ms}$ and when the flash led by more than $200 \mathrm{~ms}$, while they made fewer simultaneous responses at the $0 \mathrm{~ms}$ SOA. Model fitting demonstrated that the window of visuotactile simultaneity became narrower with development and reached adult-like levels between 9-11 years of age. Response errors decreased continuously until 11 years of age. The point of subjective simultaneity (PSS) was located on the tactile-leading side in all participants tested, indicating that 7-year olds (the youngest age tested) are adult-like on this measure. In summary, the perception of visuotactile simultaneity is not fully mature until 11 years of age. The protracted development of visuotactile simultaneity perception may be related to the need for crossmodal recalibration as the body grows, and to the developmental improvements in the ability to optimally integrate visual and tactile signals.
\end{abstract}

Keywords: Multisensory; Crossmodal; Development; Vision; Touch 


\section{Introduction}

Many daily activities involve visuotactile integration. For example, learning to dribble a basketball involves both tracking the ball visually and feeling the touch of the ball against the hand so that the correct force can be applied to the ball at the right time. The development of visuotactile integration in humans starts early in life and continues until late in childhood (see Bremner \& Spence, 2017; Burr \& Gori, 2012; Streri, 2012, for reviews). This prolonged trajectory not only results from the gradual neural maturation of each sensory system and its associated brain areas (e.g., Pihko, Nevalainen, Stephen, Okada, \& Lauronen, 2009), but also from the continuous coordination and recalibration among sensory systems as the body itself grows (Ernst, 2008; Gori, 2015).

By six months of age, and perhaps even at birth, infants appear to match primitive features (such as smooth versus nubby texture, or oval versus cross shape) presented tactilely in the mouth or on the hand to the same features presented visually (Meltzoff \& Borton, 1979; Rose, Gottfried, \& Bridger, 1981; Sann \& Streri, 2007; but see Maurer, Stager, \& Mondloch, 1999). Newborn infants are also sensitive to the spatial and temporal contingency between visual and tactile signals: when their face was stroked by a paintbrush, they looked longer at a synchronized video showing an infant's face being stroked by a paintbrush than at the same video desynchronized by 5 seconds (Filippetti, Johnson, Lloyd-Fox, Dragovic, \& Farroni, 2013; see also Filippetti, Lloyd-Fox, Longo, Farroni, \& Johnson, 2015; Zmyj, Jank, Schütz-Bosbach, \& Daum, 2011).

Even though visuotactile interactions start early in life, adult-like levels of integration are not reached until late in childhood. For example, when estimating the shape of an object using both vision and touch, children older than 8 years, like adults, integrate optimally (i.e., weight information in each sensory modality according to its reliability; see Ernst \& Banks, 2002; Gori, Del Viva, Sandini, \& Burr, 2008). In contrast, younger children do not integrate, but rather use only the information presented to either vision or touch (Gori et al., 2008; McGurk \& Power, 1980). When judging the temporal order of a visual and tactile stimulus, by 10 years of age, children like 
adults, are more accurate when the two stimuli are presented at different locations in space than when presented at the same location (e.g., Spence, Baddeley, Zampini, James, \& Shore, 2003; Spence, Shore, \& Klein, 2001); in contrast, younger children show no such spatial modulation (Röder, Pagel, \& Heed, 2013). By 12 years of age, children show adult-level precision in judging the temporal order of visual and tactile stimuli (Röder et al., 2013).

Perceiving simultaneity has long been proposed as a critical factor modulating the interaction/integration of multisensory signals (see Welch \& Warren 1980, for an early review). At the neural level, Stein and Meredith (1993) demonstrate that the response of multisensory neurons in cat's superior colliculus to the presentation of visual and tactile (or visual and auditory) stimuli is stronger than the sum of responses to individual unisensory stimuli. More critically, such superadditive multisensory neuronal responses occur only when the multisensory stimuli are presented within a certain temporal window, typically spanning a few hundred ms (Meredith, Nemitz, \& Stein, 1987). In human behavior, the presentation of a tactile stimulus can improve the processing of a simultaneously-presented visual stimulus as indicated by higher accuracy and/or shorter response latencies (Ngo \& Spence, 2010; van der Burg, Olivers, Bronkhorst, \& Theeuwes, 2009). The simultaneous presentation of multisensory signals constitutes a highly compelling situation suggesting that these stimuli plausibly originate from the same object/event (i.e., the unity assumption, see Warren, Welch, \& McCarthy, 1981; Welch \& Warren 1980; see Chen \& Spence, 2017, for a recent review). Hence, perceiving multisensory simultaneity increases the likelihood of integration of these sensory signals.

Röder et al. (2013) used temporal order judgements (TOJ) to examine developmental changes in spatial modulations of visuotactile temporal processing in childhood. In the TOJ task, the participants judge whether the visual or tactile stimulus came first. However, the study by Röder et al. did not provide precise measurements of the development of visuotactile simultaneity perception for two reasons. First, in order to manipulate the spatial congruency between the stimuli, the visual and tactile stimuli were presented randomly $32^{\circ}$ to the left and/or right of center, presumably 
resulting in the participants' attention being distributed over a wide spatial area. Such a design likely increases the difficulty of the task, especially for young children who have poorer attentional resources and control than adults. Second, developmental changes in the point of subjective simultaneity (PSS, the temporal interval that the visual and tactile signals are most likely to be perceived as simultaneous) were not measured.

The purpose of the present study was to chart the developmental trajectory of the perception that a visual and tactile stimulus are simultaneous. We used a simultaneity judgment (SJ) task in which participants judge whether or not a flash and tap are presented at the same time. The stimuli were either simultaneous, presented with the flash leading at one of six stimulus onset asynchronies (SOAs), or presented with the flash lagging at one of six SOAs. Unlike Röder et al.'s (2013) study using the TOJs task, the SJ task was adopted in the present study because adults can perceive asynchrony with smaller temporal gaps than their threshold to judge the order of the two stimuli (Love, Petrini, Cheng, \& Pollick, 2013; Shore, Gray, Spry, \& Spence, 2005). In addition, compared to Röder et al.’s (2013) study, we tested a larger number of children in each age group and minimized spatial uncertainty by always presenting the visual and tactile stimuli at midline. We then used the model proposed by García-Pérez and Alcalá-Quintana (2012a) to fit the data from each participant. One strength of this model lies in the fact that changes in both threshold and the PSS can be estimated separately and independently of the parameters associated with unimodal sensory processing; the model also allows estimates of post-perceptual processing parameters such as response errors and inattention (see also Spence et al., 2003).

\section{Methods}

\section{Participants}

There were 20 participants in each of five age groups: children aged 7 years (10 males, mean age $=7.0$ years, range $=6.8-7.3), 9$ years $(10$ males, mean age $=9.1$ years, range $=8.8-9.3), 11$

years $(10$ males, mean age $=11.0$ years, range $=10.8-11.3), 13$ years $(10$ males, mean age $=13.0$ 
years, range $=12.8-13.3)$, and adults $(8$ males, mean age $=19.9$ years, range $=18.2-22.0)$. The children were recruited from a database of parents who volunteered for their offspring to take part in research at the time of their child's birth. Adults were undergraduate students at McMaster University participating in exchange for course credits. All of the participants had normal or corrected-to-normal visual acuity in each eye confirmed by visual screening tests (20/25 vision for 7-year-olds and 20/20 vision for older participants on the Lighthouse eye chart). All of the participants were confirmed as right-handed by a handedness questionnaire (Peters, 1998). An additional six participants were tested but not included in the final analysis because they did not complete the experiment (one 7-year-old and one 13-year-old), did not pass visual screening (one 13-year-old), did not pass the handedness questionnaire (one 9-year-old and one adult), or did not feel the tactile stimulus clearly (by self-report, one adult). We obtained written consent from the parents of children and adult participants, and written assent from children. All of the participants were naïve regarding the purpose of the study. The study was approved by the Research Ethics Board of McMaster University and conformed to the Tri-Council Statement on Ethical Conduct of Research Involving Humans (TCPS2) (Canada).

\section{Apparatus and Stimuli}

The participants were seated in a dimly-lit room with their head on a chin rest located $50 \mathrm{~cm}$ from the monitor where the visual stimuli were presented. A gray ring with a $2^{\circ}$ inner diameter and $0.06^{\circ}$ thickness was displayed in the center of a black background on the monitor throughout the experiment. The visual stimulus consisted of a $2^{\circ}$ white disc presented in the middle of the grey ring for $17 \mathrm{~ms}$ ( 1 frame at the $60 \mathrm{~Hz}$ refresh rate). The tactile stimulus was a tap induced by a pin moving up for $17 \mathrm{~ms}$ and then moving down, generated by a custom built solenoid-based mechanical device. The participants placed their right index finger on top of the tactile device, which was situated in front of the monitor and about $20^{\circ}$ below the ring so as to align with the participant's body midline. The presentation of the stimuli was controlled by Matlab (MathWorks Inc., Natick, MA) and Psychtoolbox extensions (Brainard, 1997; Kleiner, Brainard, \& Pelli, 2007; 
Pelli, 1997). During the experiment, the participants heard white noise presented continuously over closed-ear headphones in order to mask the noise produced by the operation of the tactile device.

\section{Design}

Two factors were manipulated: Age (7, 9, 11, 13 years, and Adult) and SOA (-1200, -800, -400, $-300,-200,-100,0,100,200,300,400,800$, and $1200 \mathrm{~ms}$ ), where negative values indicate that the tap was presented first, and positive values indicate that the flash was presented first. The stimulus durations and SOA between the flash and the tap were confirmed with an oscilloscope. Each SOA was tested twice in each block. All of the participants completed 10 blocks of trials, giving rise to 260 trials in total. The participants were given a short break between blocks, and given breaks during a block if necessary. It typically took the participants 30 to 50 minutes to complete the experiment.

\section{Procedure}

During the experiment, the participants were instructed to fixate the ring. The participants' task was to say "yes" if they perceived the onsets of the flash and tap at the same time, or "no" if they perceived their onsets at different times. An experimenter sat beside the participant and keyed their answers into the computer. The experimenter also monitored whether the participant appeared to be fixating the ring and if not, stopped the experiment for a break.

Two practice sessions were conducted prior to the main experiment. The first practice session consisted of eight trials: four with $0 \mathrm{~ms}$ SOA and four with each of the $-1200,-800,800$, and 1200 ms SOAs. In the first round, the participants practiced without the masking noise so that the experimenter could communicate with them to ensure that they felt the tap clearly and understood the task. In the second round, the participants practiced with the masking noise presented through the headphones. All of the participants achieved $85 \%$ accuracy (i.e., no more than one error) in the second round. The second practice session consisted of one trial for each of the 13 SOAs used in the main experiment and was designed to familiarize the participants with the experimental procedure. 
There were no accuracy requirements for this second practice session. No feedback was given during either practice session, except for general encouragement.

\section{Results}

\section{Proportion of simultaneous responses}

The mean proportion of simultaneous responses at each SOA for each age group is shown in Figure 1. The data were submitted to a two-way analysis of variance (ANOVA) with a betweenparticipant factor of Age and a within-participant factor of SOA. Both the main effects of Age $\left(F(4,95)=7.64, M S E=0.17, p<.001, \eta_{p}{ }^{2}=0.24\right)$ and SOA $(F(12,1140)=454.27, M S E=0.02, p$

$\left.<.001, \eta_{p}{ }^{2}=0.83\right)$ were significant. Critically, their interaction was also significant $(F(48,1140)=$ 4.22, MSE $\left.=0.02, p<.001, \eta_{p}{ }^{2}=0.15\right)$. Table 1 presents the results of one-way ANOVAs on the factor of Age at each SOA and the post-hoc tests at the SOAs where there was a significant simple main effect of Age (Dunnett test, two-tailed). In summary, the Age effect was significant at 10 out of the 13 SOAs, with the exceptions being the $-200,-100$, and $100 \mathrm{~ms}$ SOAs. Compared to adults, more simultaneous responses were made by 7-year-olds when the tap led the flash by 300 ms or more, and by 7- and 9-year-olds when the tap lagged behind the flash by $200 \mathrm{~ms}$ or more. On the other hand, both 7- and 9-year-olds made fewer simultaneous responses at the $0 \mathrm{~ms}$ SOA (all $t(38) \geq$ 2.60, $p$ s $<.05$, Cohen's $d \geq 0.85)$. 


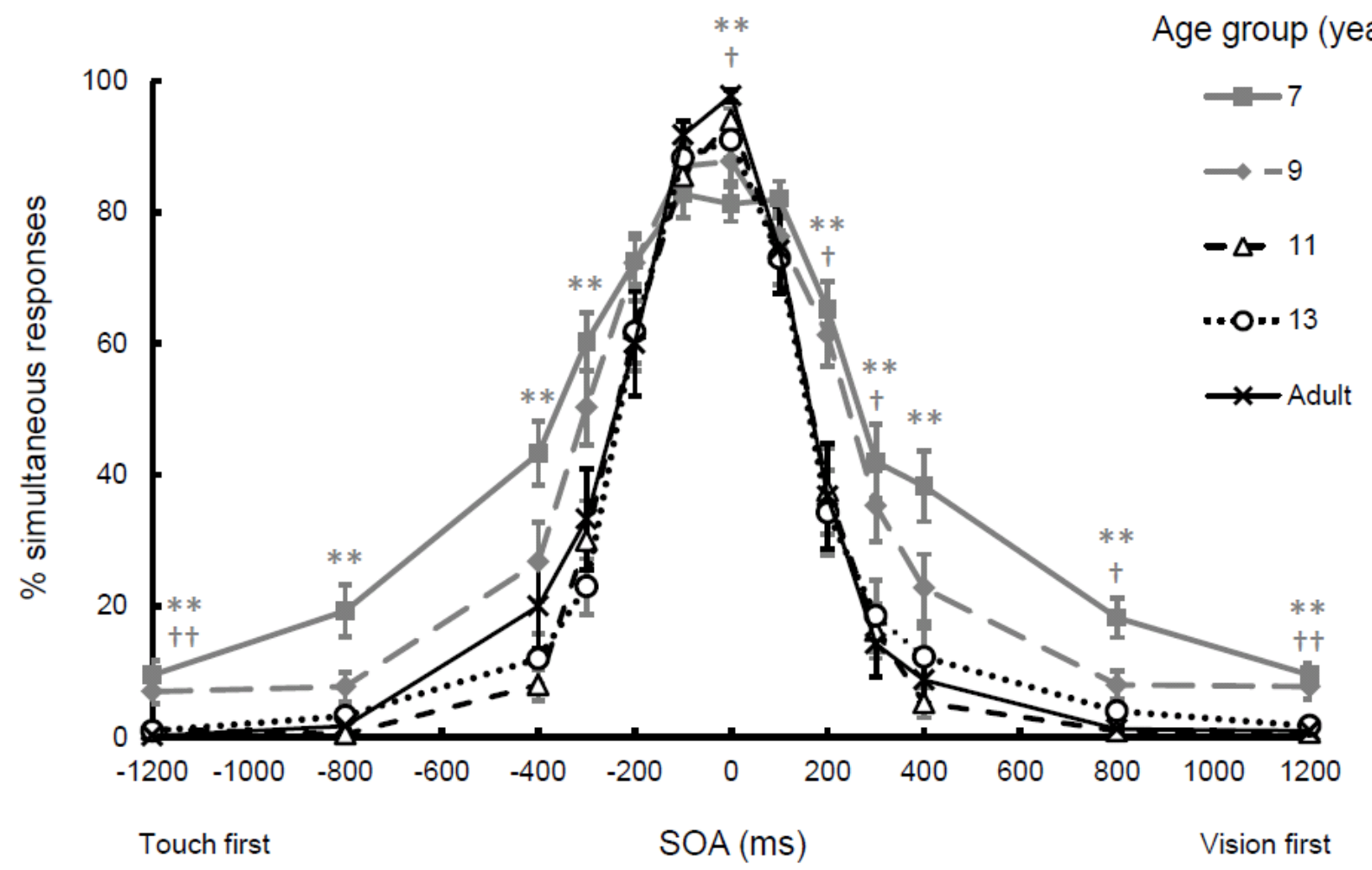

Figure 1. The mean percentage of simultaneous responses at each stimulus onset asynchrony (SOA) for each of the five age groups of participants. Error bars indicate \pm 1 standard error of the mean. A significant difference between 7-year-olds and adults is indicated by $* *(p<.01)$; a significant difference between 9-year-olds and adults is indicated by $\dagger(p<.05)$ or $\dagger \dagger(p<.01)$. 
Table 1. Percentage of simultaneous responses for each age group, the results of one-way ANOVAs, and post-hoc tests (Dunnett) for the proportion of simultaneous responses at each SOA. Negative SOAs indicate the conditions where the tap was presented first, while positive SOAs indicate conditions where the flash was presented first.

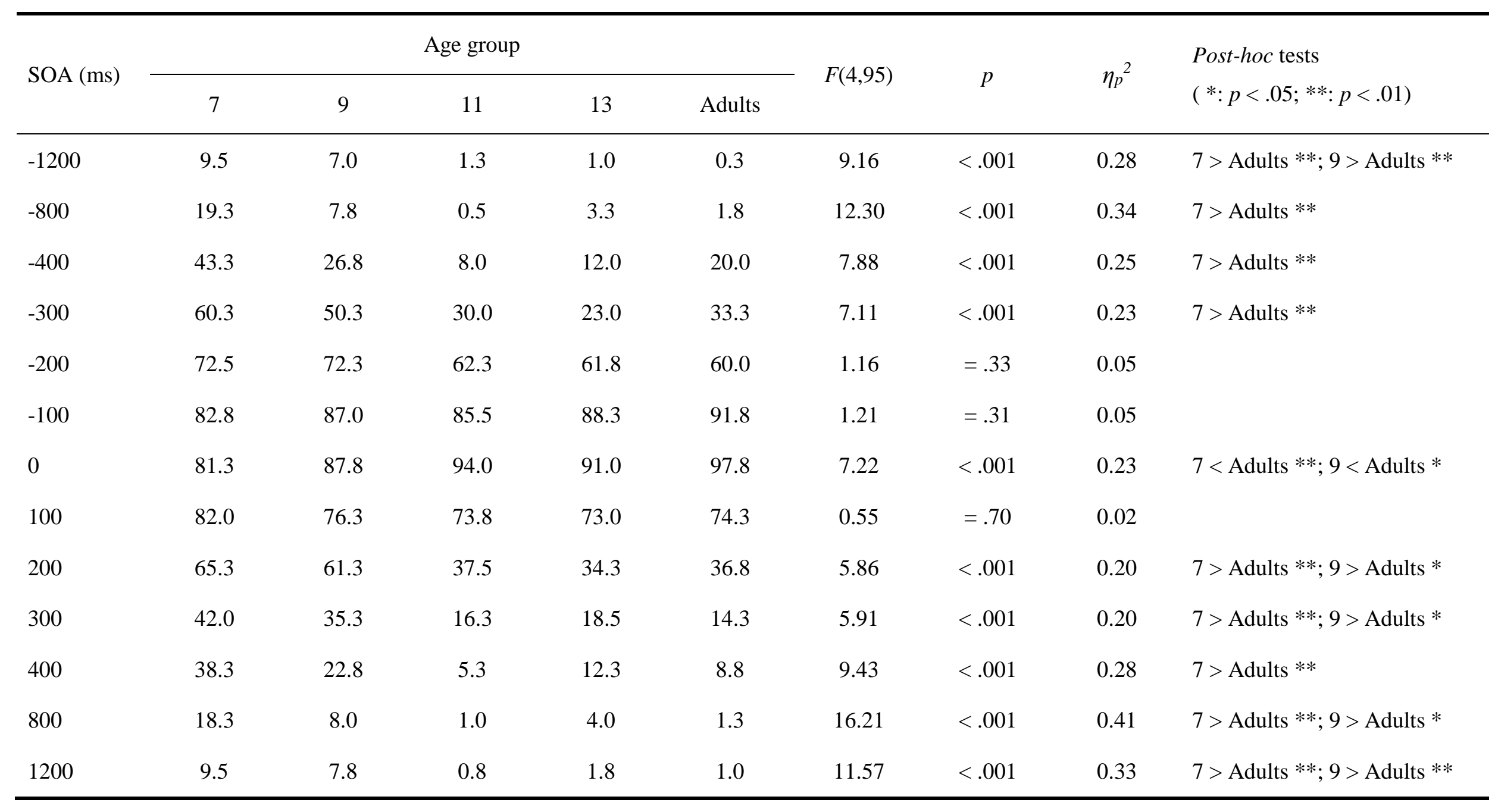




\section{Estimated parameters of simultaneity judgment}

Individual data were fit with the Matlab routine for the SJ task (Alcalá-Quintana \& GarcíaPérez, 2013). This routine is based on an independent-channels model for judgment tasks involving stimulus timing as proposed by García-Pérez and Alcalá-Quintana (2012a). In this model, it is assumed that each signal is processed in each sensory system separately and then merged to a mechanism decoding their arrival time. The sensory processing time required for a signal is modeled using an exponential distribution that is determined by two parameters: the processing time $(\tau i)$ and the processing variability $(\lambda i)$. In the present study, the difference in processing time between the tactile and visual stimuli (i.e., $\tau=\tau \mathrm{T}-\tau \mathrm{V}$ ) and the processing variability in the tactile and visual modalities ( $\lambda \mathrm{T}$ and $\lambda \mathrm{V}$, respectively) were estimated. On those trials in which the tap and flash were presented at a specific SOA, the difference in processing time for the two stimuli would form a bilateral exponential distribution that is determined by $\lambda \mathrm{V}, \lambda \mathrm{T}$, and $\tau$.

We defined the PSS as the midpoint between 50\% simultaneous responses on the tactileleading and the visual-leading sides of the distribution, with half of this range representing the threshold of simultaneity perception, which is the resolution parameter $(\delta)$. A "simultaneous" response would be made when the processing time difference is smaller than the resolution parameter. Hence, the larger the value of the resolution parameter, the wider the visuotactile simultaneity window. Finally, we estimated response errors that occurred when participants incorrectly reported "yes" in tactile-leading trials $(\varepsilon T F)$ or visual-leading trials $(\varepsilon V F)$, and when they incorrectly reported "no" in the 0 -ms trials $(\varepsilon S)$. Note that these response errors include both participants' lapses caused by blink or inattention as well as their mistakes in responding, since these two types of errors are hard to distinguish (see García-Pérez \& Alcalá-Quintana, 2012b). The starting values used to fit the data in the present study were set as follows: LamBounds $=[1 / 500$ 1/1]; TauBounds $=[-$ Inf Inf $] ;$ DeltaBounds $=[0$ Inf $] ;$ LamTStart $=[1 / 70$ 1/10]; LamRStart $=[1 / 70$ 1/10]; TauStart $=\left[-70\right.$ 70]; DeltaStart $=\left[\begin{array}{ll}20 & 150\end{array} ;\right.$ ErrStart $=[0.05] ;$ BiaStart $=[0.5] ;$ Model $=1 ;$ 
SampleSize $=1500 ;$ ConfCoef $=95 ;$ FixedSeed $=$ true $($ see also Chen, Shore, Lewis, $\&$ Maurer, 2016).

Each of the estimated parameters was submitted to a one-way ANOVA with Age as the factor (see Table 2). There was a significant Age effect for the resolution parameter $(\delta, F(4,95)=7.69$, $M S E=13687.25, p<.001, \eta_{p}{ }^{2}=0.25$; see Figure 2A). Post-hoc tests (Dunnett, one-tailed, since it is assumed that children have a wider window than adults, see Röder et al., 2013) revealed that $\delta$ was larger for 7-year-olds $(t(38)=3.28, p<.001$, Cohen's $d=1.06)$ than for adults, but not for 11$(t(38)=-0.53, p=.91$, Cohen's $d=0.17)$ or 13-year-olds $(t(38)=-0.22, p=.86$, Cohen's $d=0.07)$. The data for 9-year-olds appears transitional: the mean is larger $(300.4 \mathrm{~ms})$ than in adults $(230.8$ ms) but the Dunnett test was not significant $(t(38)=2.14, p=.095$, Cohen's $d=0.69)$. This pattern of results suggests that the width of the visuotactile simultaneity window approaches adult levels at around 9 years of age.

The PSS of all five age groups was negative (i.e., on the tactile-leading side, 7-year-olds: $t(19)$ $=-2.87, p<.05$, Cohen's $d=0.64$; 9-year-olds: $t(19)=-2.22, p<.05$, Cohen's $d=0.50 ; 11$-yearolds: $t(19)=-5.61, p<.001$, Cohen's $d=1.25$; 13-year-olds: $t(19)=-2.12, p<.05$, Cohen's $d=$ 0.47; Adult: $t(19)=-4.29, p<.001$, Cohen's $d=0.96$ ), and there was no significant Age effect $\left(F(4,95)=1.33, M S E=2803.02, p=.26, \eta_{p}{ }^{2}=0.05 ;\right.$ see Figure 2B $)$. Thus, in the present study, the PSS was located at the tactile-leading side by 7 years of age, the youngest age tested.

There was no significant effect of Age for the three parameters associated with sensory processing: tactile processing variability $\left(\lambda \mathrm{T}, F(4,95)=2.21, M S E=0.05, p=.07, \eta_{p}{ }^{2}=0.09\right)$, visual processing variability $\left(\lambda \mathrm{V}, F(4,95)=0.59, M S E=0.08, p=.67, \eta_{p}{ }^{2}=0.02\right)$, and arrival time difference $\left(\tau, F(4,95)=1.72, M S E=12321.34, p=.15, \eta_{p}{ }^{2}=0.07\right)$. The marginal significance of tactile processing variability comes mainly from a smaller variability in children aged 11 years than in adults $(\mathrm{t}(38)=-2.76, p<.05$, Cohen's $d=0.90)$, suggesting that children's tactile system, if there is any difference, was more rather than less reliable than adults. 
These results therefore suggest that by 7 years of age, sensory processing of a simple tap and flash in the temporal domain is already adult-like. The $\tau$ was positive and significantly different from 0 in adults $(t(19)=3.16, p<.01$, Cohen's $d=0.71)$, suggesting a longer processing time for tactile than visual stimuli. However, the $\tau$ was not significantly different from 0 in the four age groups of children (7-year-olds: $t(19)=2.01, p=.06$, Cohen's $d=0.45)$, 9-year-olds $(t(19)=1.85$, $p=.08$, Cohen's $d=0.41), 11$-year-olds $(t(19)=1.43, p=.17$, Cohen's $d=0.32)$, and 13-year-olds $(t(19)=0.05, p=.96$, Cohen's $d=0.01)$.

In contrast, there was a significant Age effect for the three parameters related to response errors. Specifically, the age effect was significant when the tactile stimulus led $(\varepsilon T F, F(4,95)=8.40$, $\left.M S E=0.004, p<.001, \eta_{p}{ }^{2}=0.26\right)$, when the two stimuli were simultaneous $(\varepsilon S, F(4,95)=4.52$, $\left.M S E=0.01, p<.005, \eta_{p}{ }^{2}=0.16\right)$, and when the visual stimulus led $(\varepsilon \mathrm{VF}, F(4,95)=12.31, M S E=$ 0.003, $p<.001, \eta_{p}{ }^{2}=0.34$ ). Post-hoc tests (Dunnett, one-tailed, given that children should make more errors than adults, see Chen et al., 2016) revealed that response errors were higher for 7- and 9-year-olds than for the adults when the tactile stimulus led $(t(38) \geq 2.95, p$ s $<.05$, Cohen's $d \geq$ 0.96), in the simultaneous condition $(t(38) \geq 2.81, p s<.01$, Cohen's $d \geq 0.91)$, and when the visual stimulus led $(t(38) \geq 4.06, p$ s $<.001$, Cohen's $d \geq 1.32)$. These results suggest that children aged 7 and 9 years were more likely to make response errors than adults in general.

We also analyzed the data using the same exclusion criteria that Chen et al (2016) had used for outlier detection. Specifically, in plotting the developmental trajectory of audiovisual simultaneity perception, Chen et al. (2016) excluded participants who had: 1) simultaneous responses at \pm 1200 ms SOA were higher than the mean plus two standard deviations (SDs) of that age group; and 2) simultaneous responses at the $0 \mathrm{~ms}$ SOA were lower than $50 \%$ or the mean minus two SDs of that age group. The use of these criteria in the current study led to the exclusion of two participants in each of the four age groups of children, and one adult. The results remained the same except that the Age effect on tactile processing variability was significant $(\lambda \mathrm{T}, F(4,86)=3.20, M S E=0.04, p<.05$, $\eta_{p}{ }^{2}=0.13$ ). Post-hoc tests (Dunnett, two-tailed) demonstrated that the tactile processing variability 
was smaller in children aged 7 and 11 years than in adults (both $\mathrm{t}(35) \leq-2.57, p \mathrm{~s}<.05$, Cohen 's $d \geq$ 0.87). See Appendix A for the summary and statistical results.

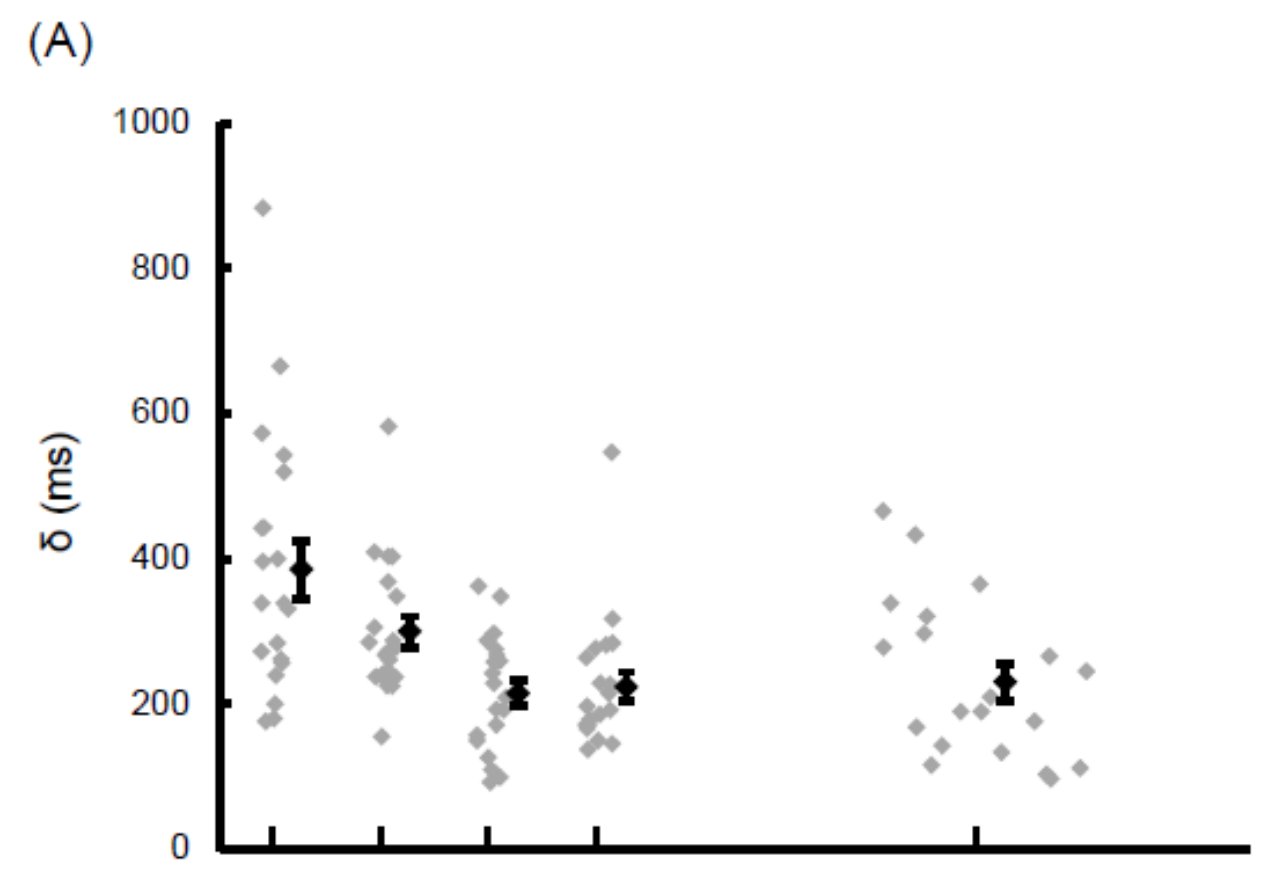

(B)

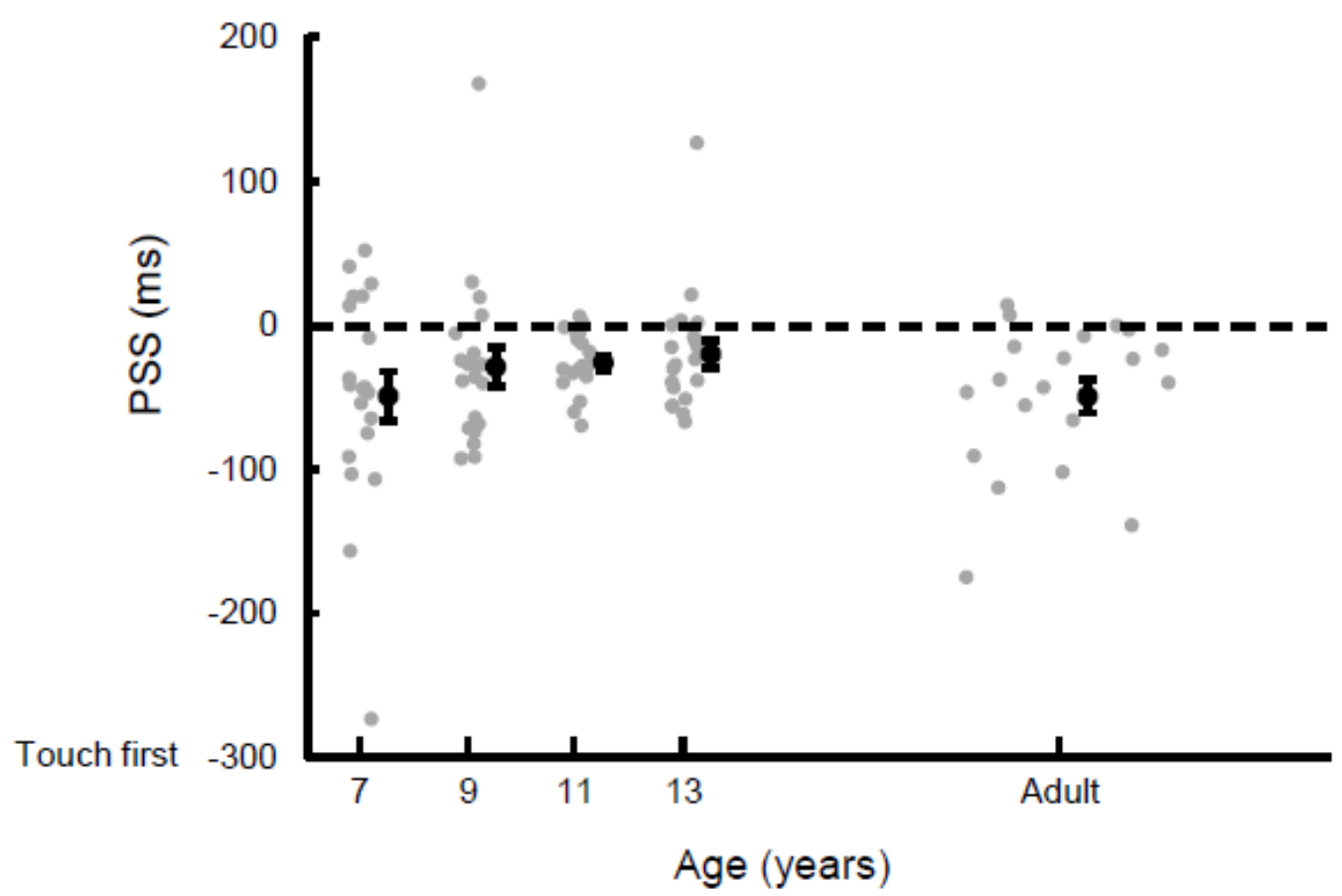

Figure 2. (A) The threshold of simultaneity perception ( $\delta$ ), and (B) point of subjective simultaneity (PSS) as a function of age. The mean PSS in each age group was negative indicating the conditions where the tap was presented first. Gray dots represent individual data, black dots represent the mean for each age group, and error bars indicate \pm 1 standard error of the mean. 
Table 2. The mean (in bold) and SE (in parentheses) of estimated parameters of the simultaneity judgment task for each age group.

\begin{tabular}{|c|c|c|c|c|c|c|c|c|c|}
\hline \multirow{2}{*}{ Parameter } & \multicolumn{5}{|c|}{ Age group } & \multirow{2}{*}{$F(4,95)$} & \multirow{2}{*}{$p$} & \multirow{2}{*}{$\eta_{p}^{2}$} & \multirow{2}{*}{$\begin{array}{l}\text { Post-hoc tests } \\
(*: p<.05 ; * *: p<.01)\end{array}$} \\
\hline & 7 & 9 & 11 & 13 & Adults & & & & \\
\hline$\delta$ & $\begin{array}{l}\mathbf{3 8 5 . 8} \\
(40.3)\end{array}$ & $\begin{array}{l}\mathbf{3 0 0 . 4} \\
(21.2)\end{array}$ & $\begin{array}{l}\mathbf{2 1 4 . 8} \\
(17.8)\end{array}$ & $\begin{array}{l}\mathbf{2 2 3 . 9} \\
(20.5)\end{array}$ & $\begin{array}{l}\mathbf{2 3 0 . 8} \\
(24.7)\end{array}$ & 7.69 & $<.001$ & 0.25 & $7>$ Adults $* *$ \\
\hline PSS & $\begin{array}{l}-49.0 \\
(17.1)\end{array}$ & $\begin{array}{l}\mathbf{- 2 8 . 8} \\
(13.0)\end{array}$ & $\begin{array}{l}-25.8 \\
(4.6)\end{array}$ & $\begin{array}{l}\mathbf{- 2 0 . 0} \\
(9.4)\end{array}$ & $\begin{array}{l}-49.2 \\
(11.5)\end{array}$ & 1.33 & $=.26$ & 0.05 & \\
\hline$\lambda \mathrm{T}$ & $\begin{array}{c}\mathbf{0 . 0 9} \\
(0.05)\end{array}$ & $\begin{array}{c}\mathbf{0 . 1 5} \\
(0.06)\end{array}$ & $\begin{array}{c}\mathbf{0 . 0 4} \\
(0.02)\end{array}$ & $\begin{array}{c}\mathbf{0 . 0 9} \\
(0.04)\end{array}$ & $\begin{array}{c}\mathbf{0 . 2 4} \\
(0.07)\end{array}$ & 2.21 & $=.07$ & 0.09 & \\
\hline$\lambda \mathrm{V}$ & $\begin{array}{c}\mathbf{0 . 1 8} \\
(0.07)\end{array}$ & $\begin{array}{c}\mathbf{0 . 0 8} \\
(0.05)\end{array}$ & $\begin{array}{c}\mathbf{0 . 2 0} \\
(0.07)\end{array}$ & $\begin{array}{c}\mathbf{0 . 1 4} \\
(0.06)\end{array}$ & $\begin{array}{c}\mathbf{0 . 1 4} \\
(0.07)\end{array}$ & 0.59 & $=.67$ & 0.02 & \\
\hline$\tau$ & $\begin{array}{c}76.2 \\
(37.9)\end{array}$ & $\begin{array}{c}\mathbf{4 1 . 0} \\
(22.2)\end{array}$ & $\begin{array}{c}\mathbf{1 7 . 4} \\
(12.2)\end{array}$ & $\begin{array}{c}1.2 \\
(22.5)\end{array}$ & $\begin{array}{c}70.2 \\
(22.2)\end{array}$ & 1.72 & $=.15$ & 0.07 & \\
\hline$\varepsilon \mathrm{TF}$ & $\begin{array}{c}\mathbf{0 . 1 0} \\
(0.02)\end{array}$ & $\begin{array}{c}\mathbf{0 . 0 6} \\
(0.02)\end{array}$ & $\begin{array}{c}\mathbf{0 . 0 1} \\
(0.004)\end{array}$ & $\begin{array}{c}\mathbf{0 . 0 1} \\
(0.01)\end{array}$ & $\begin{array}{c}\mathbf{0 . 0 1} \\
(0.004)\end{array}$ & 8.40 & $<.001$ & 0.26 & $7>$ Adults $* * ; 9>$ Adults $*$ \\
\hline$\varepsilon S$ & $\begin{array}{c}\mathbf{0 . 0 9} \\
(0.03)\end{array}$ & $\begin{array}{c}\mathbf{0 . 1 0} \\
(0.03)\end{array}$ & $\begin{array}{c}\mathbf{0 . 0 3} \\
(0.01)\end{array}$ & $\begin{array}{c}\mathbf{0 . 0 3} \\
(0.01)\end{array}$ & $\begin{array}{c}\mathbf{0 . 0 2} \\
(0.01)\end{array}$ & 4.52 & $<.005$ & 0.16 & $7>$ Adults $* * ; 9>$ Adults $* *$ \\
\hline$\varepsilon V F$ & $\begin{array}{c}\mathbf{0 . 1 0} \\
(0.02)\end{array}$ & $\begin{array}{c}\mathbf{0 . 0 7} \\
(0.02)\end{array}$ & $\begin{array}{c}\mathbf{0 . 0 1} \\
(0.003)\end{array}$ & $\begin{array}{c}\mathbf{0 . 0 2} \\
(0.01)\end{array}$ & $\begin{array}{c}\mathbf{0 . 0 1} \\
(0.004)\end{array}$ & 12.31 & $<.001$ & 0.34 & $7>$ Adults $* * ; 9>$ Adults $* *$ \\
\hline
\end{tabular}

$\delta$ : resolution (threshold of simultaneity perception); PSS: point of subjective simultaneity; $\lambda \mathrm{T}$ : processing variability of tactile stimulus; $\lambda \mathrm{V}$ : processing variability of visual stimulus; $\tau$ : processing time difference between tactile and visual stimulus $(\tau T-\tau V)$; $\varepsilon \mathrm{TF}$ : response errors in the tactile-leading trials; $\varepsilon S$ : response errors in the simultaneous trials; $\varepsilon \mathrm{VF}$ : response errors in the visual-leading trials. 


\section{Discussion}

The developmental trajectory of the perception of visuotactile simultaneity was measured by asking participants to judge whether a flash on the monitor and a tap to the finger occurred simultaneously. Compared to adults, children aged 7 years judged the flash and tap to be simultaneous over a wider range of SOAs both when the tap came first and when the flash came first, but children aged 9 years did so mainly when the flash came first. Children aged 11 and 13 years performed the same as adults. Model fitting results demonstrated that the wider window observed for 7-year-olds and, to a lesser extent, for 9-year-olds, can be attributed to their higher threshold of visuotactile simultaneity and higher response errors. In contrast, the midpoint of the window (i.e., the PSS), as in adults, was located on the tactile leading side by 7 years old (the youngest age tested).

These results therefore indicate that children reach adult-like levels of perception of visuotactile simultaneity between 9 and 11 years of age. This age is two years later than the perception of audiovisual simultaneity, which becomes adult-like between 7 and 9 years of age when tested using the same visual flash paired with a white noise burst (Chen et al., 2016). The earlier maturation for audiovisual than visuotactile simultaneity perception may arise from the ubiquitous interactions between vision and audition (e.g., through daily speech communications). Additionally, rudimentary forms of temporal and spatial mappings between visual and auditory signals appear at birth (Lewkowicz, Leo, \& Simion, 2010; Morrongiello, Fenwick, \& Chance, 1998), whereas these mappings appear later between vision and touch (see Bremner \& Spence, 2017, for a review). Different developmental trajectories suggest that the audiovisual and visuotactile perception of simultaneity are underpinned by different mechanisms (see also Noel, Wallace, Orchard-Mills, Alais, \& van der Burg, 2015; van der Burg, Orchard-Mills, \& Alais, 2015; though see Machulla, Di Luca, \& Ernst, 2016; see Vroomen \& Keetels, 2010, for a review). This argument is bolstered by recent evidence demonstrating that early visual deprivation leads to later abnormal perception of 
audiovisual simultaneity, whereas the perception of visuotactile simultaneity is spared (Chen, Lewis, Shore, \& Maurer, 2017).

One may worry whether a comparison between the developmental trajectories of the perception of audiovisual and visuotactile simultaneity is valid. This concern arises from the fact that stronger stimuli tend to be processed more rapidly (Jaśkowsky \& Verleger, 2000; Smith, 1933), plausibly leading to an inaccurate measure of the developmental trajectory of the perception of multisensory simultaneity. In our previous study on the developmental trajectory of audiovisual simultaneity perception (Chen et al, 2016) and in the current study on the developmental trajectory of visuotactile simultaneity perception, the visual stimuli were the same (i.e., a white flash); the auditory and tactile stimuli were clearly above threshold, although there was no way to match their intensity. The shape of the developmental trajectory would be distorted only if the influence of stimulus intensity on unimodal processing time differed at different ages. Critically, the PSS should be more susceptible to any such processing time difference than the width of multisensory simultaneity window (i.e., the threshold). However, in both our audiovisual and visuotactile studies, we did not observe any significant changes of the PSS from the youngest ages tested to adulthood. We therefore suggest that, in our studies, when stimulus intensity was sufficiently above threshold, it is unlikely to have influenced our measure of the developmental trajectories of audiovisual and visuotactile simultaneity perception.

\section{Width of the visuotactile simultaneity window: Changes after 7 years of age}

The threshold $(\delta)$ of visoutactile simultaneity perception is represented by half of the width of the simultaneity window at $50 \%$ simultaneous responses. The mean threshold was larger in 7 -yearolds than in adults, with a tendency in the same direction at age 9 years of age. By 11 years of age, it was unambiguously adult-like. Moreover, as shown in Figure 2A, the variability in 7-year-olds was greater than that in older children, primarily because some 7-year-olds had already reached adult-like thresholds, while others performed much worse. Such large individual variability in young children may be related not only to their different rate of sensory and perceptual 
development, but also to their physical development (see Long Developmental Trajectories of Visuotactile Perception, below).

Adults find it more difficult to separate two temporally-close stimuli (i.e., higher thresholds) when they are presented in different modalities than when they are presented in the same modality (Fujisaki \& Nishida, 2010; Virsu, Oksanen-Hennah, Vedenpää, Jaatinen, \& Lahti-Nuuttila, 2008). To assess whether the same is true in children, Röder et al. (2013) compared their multisensory visuotactile results to the unimodal tactile results reported by Pagel, Heed, and Röder (2009) and suggested that the precision of visuotactile simultaneity perception develops later than that of unimodal tactile simultaneity perception. Consistently, here we observed that children reach adultlevel thresholds of visuotactile simultaneity perception at 9-11 years of age, an age range later than when they reach adult-level thresholds of visual temporal resolution (which occurs by 4 years of age, see Ellemberg, Lewis, Liu, \& Maurer, 1999). Further evidence comes from the results of estimated sensory parameters in the current study: the variabilities of temporal processing associated with the visual and tactile systems (indexed by $\lambda \mathrm{V}$ and $\lambda \mathrm{T}$, respectively) were similar to those of adults by 7 years of age (the youngest age tested in the present study). The earlier developing temporal precision in unimodal visual and tactile systems is likely a necessary prerequisite for the later development of viosuotactile simultaneity perception (see Chen et al., 2016, for a similar conclusion for the development of audiovisual simultaneity perception).

\section{Response errors of visuotactile simultaneity judgments: Reduced until 11 years of age}

The final step in reaching the adults' window of visuotactile simultaneity perception arises from a reduction in the number of errors (indexed by the $\varepsilon \mathrm{TF}, \varepsilon \mathrm{S}$ and $\varepsilon \mathrm{VF}$ for the tactile-leading, simultaneous, and visual-leading conditions, respectively), none of which reach adult levels until 11 years of age. In García-Pérez and Alcalá-Quintana's (2012a, b) model, higher response errors are attributed to the participants' blink or inattention as well as their mistakes in responding. This is consistent with results showing that children's executive attentional control develops and reaches adult-like levels between 7-10 years of age, depending on the stimuli tested (e.g., Ridderinkhof, van 
der Molen, Band, \& Bashore, 1997; Rueda et al., 2004; Shore, Burack, Miller, Joseph \& Enns, 2006).

This late reduction of response errors contrasts with judgments of audiovisual simultaneity obtained with the same paradigm and same visual stimulus, where response errors were adult-like by 9 years of age. The temporal encoding of tactile signals is modulated by limb posture, as demonstrated by the crossing-hand deficits in both unimodal tactile (Pagel et al., 2009; Shore, Spry, \& Spence, 2002) and bimodal visuotactile tasks (Röder et al., 2013; Spence et al., 2003). These results likely arise from the necessity of mapping between the external reference frame used by vision and the somatotopic reference frame used by touch when encoding the timing of visual and tactile signals (Azañón \& Soto-Faraco, 2008; Heed \& Azañón, 2014). In the present study, the tactile signal was presented $20^{\circ}$ below the visual signal. It is possible that response errors in judging simultaneity can be reduced to adult levels at younger ages if the coordination of visual and tactile is minimized by presenting both stimuli at fixation (e.g., Machulla et al., 2016).

\section{Long developmental trajectories of visuotactile perception}

Multisensory simultaneity has long been demonstrated as a critical factor determining whether (or how likely) an observer is to integrate two stimuli as a single object/event (Chen \& Spence, 2017; Stein \& Meredith, 1993; Welch \& Warren, 1980). Here, we demonstrate that the window of visuotactile simultaneity does not become adult-like until 11 years of age. Similarly, combining TOJs with spatial uncertainty, Röder et al. (2013) found a fairly late age for the adult-like precision for visuotactile perception of discriminating the temporal order of stimuli, namely 12 years of age.

Given that the human body grows and each sensory system develops at different rates until late childhood or adolescence, Ernst (2008) suggested that the development of visuotactile integration may be protracted because each sensory system retains its own signals in order to optimize reorganization and recalibration both within and across modalities, rather than integrate the information into a seamless unified representation. Typically, the sensory modality that delivers more accurate estimates (though not necessarily more precise) calibrates the other during the 
development of multisensory systems (Burr \& Gori, 2012; Gori, 2015). The importance of crossmodal calibration has been demonstrated both in unisensory perception (such as haptic orientation and auditory localization 'educated' by vision, see Gori, Sandini, Martinoli, \& Burr, 2010, 2014) and in crossmodal perception (such as audiovisual and visuotactile simultaneity perception, see Chen et al., 2017).

Until 9 years of age, the size of the head relative to the body and limbs decreases, and the length of legs relative to stature increases; in contrast, during the rapid body growth in adolescence, the head, torso, and legs remain similar in proportion (see Bremner, Holmes, \& Spence, 2012, for a review). By 8 years of age, children have demonstrated optimal integration following Bayes' rule in some cases of visuotactile perception (e.g., Gori et al., 2008). Optimal integration is a flexible ability that can be adjusted rapidly in various conditions, as shown by the ability of adults to maintain optimal visuotactile integration when using tools (Takahashi, Diedrichsen \& Watt, 2009). Despite continued growth in adolescence, the maintenance of body proportions and the flexibility of optimal integration may allow adolescents to quickly accommodate the growing body in the process of visuotactile integration. This analysis is consistent with our findings that, in the temporal domain, the precision and accuracy of integration do not change after 11 years of age.

\section{PSS shifted to the tactile-leading side by 7 years of age}

Despite the changes in precision and response errors, the PSS was already on the tactile leading side like that of adults by 7 years of age. The location of the visuotactile PSS is determined by at least two factors: the different times required for visual and tactile processing before their arrival time is encoded, and the participants' attention favoring one or other of the relevant sensory modalities.

The time required for tactile transduction is positively correlated with the distance between the stimulated body-part and the head, with a velocity of roughly $55 \mathrm{~m} / \mathrm{sec}$ (Bergenheim, Johansson, Granlund, \& Pedersen, 1996; Macefield, Gandevia, \& Burke, 1989). Hence, tactile processing time should increase as the body grows during development. Indeed, the tactile processing time was 
longer than visual processing time (estimated by $\tau=\tau \mathrm{T}-\tau \mathrm{V}$ ) in adults. However, the difference was not significant in the four age groups of children. Hence, the processing time difference of visual and tactile signals cannot explain the fact that the PSS has already shifted to its adult location by the time that the typically-developing child reaches 7 years of age.

A more likely explanation is that the participants' attention favored one of the sensory modalities over the other. In human adults, attention is naturally biased toward vision over touch (Klein, 1977; Posner, Nissen, \& Klein, 1976; Spence et al., 2001). The sensory signal in the attended modality is processed faster, a phenomenon known as crossmodal prior entry (Grabot \& van Wassenhove, 2017; Spence et al., 2001; Zampini, Shore, \& Spence, 2005). Hence, biased attention toward vision would likely lead to the faster processing of visual than tactile signals. Consequently, the tactile stimulus would need to be presented first in order for visuotactile simultaneity to be perceived, and the PSS would, therefore, shift to the tactile-leading condition. Supporting evidence for human attention being biased toward vision over touch comes from the visual dominant Colavita effect; that is, a tactile stimulus may go undetected when it is presented together with a visual stimulus, even though the tactile and visual stimuli are easily detected when presented alone (Hartcher-O’Brien, Gallace, Krings, Koppen, \& Spence, 2008; Hecht \& Reiner, 2009; see Spence, Parise, \& Chen, 2012, for a review). The sensory dominance of vision over touch has also been demonstrated in children with mean age of 12 years (ranging from 8.6 to 16.0 years, Hermelin \& O'Connor, 1964).

Nevertheless, we cannot exclude the possibility that the flash, but not the tap (presented $20^{\circ}$ below the flash), was presented at the fixated location and therefore its processing was enhanced. Previous studies (see Table 3) demonstrated that adults' PSS was located at the visual leading side when the visual target was presented in the periphery (Poliakoff, Shore, Lowe, \& Spence, 2006; Spence et al., 2001, 2003), but located at the tactile-leading side when the visual target was presented at fixation (present study; Noel et al., 2015; van der Burg et al., 2015; Zhou, 2016). In any 
event, under the present conditions, attention appears to enhance visual signal processing in all age groups, from age 7 years to adulthood.

\section{Conclusions}

In summary, different components of the window of visuotactile simultaneity mature at different ages: the PSS has shifted to the tactile-leading side by 7 years of age (the youngest age tested), the threshold has decreased to adult levels by 9-11 years of age, and responses errors were reduced to adult levels by 11 years of age. The maturation of the window of visuotactile simultaneity in late childhood is similar to the maturation of visuotactile integration and visuotactile interactions in shape, size, and space perception (Cowie, Sterling, \& Bremner, 2016; Gori et al., 2008; Gori, Giuliana, Sandini, \& Burr, 2012). These long visuotactile developmental trajectories are likely related to visuotactile recalibrations as the body grows (e.g., Ernst, 2008), and the development of optimal integration for multisensory signals (e.g., Gori, 2015). The visuotactile simultaneity window is fully adult-like two years later than that of the audiovisual simultaneity window (Chen et al., 2016). These results suggest multisensory perception of simultaneity for different sensory combinations may have unique, rather than shared, mechanisms. 
Table 3. Summary of the estimated visuotactile point of subjective simultaneity (PSS) reported in previous studies. Negative PSS values indicate that the tactile stimulus had to be presented first, whereas positive values indicate that the visual stimulus had to be presented first.

\begin{tabular}{|c|c|c|c|c|c|}
\hline Study & Visual stimulus & Tactile stimulus & Stimulus location & Task & PSS (ms) \\
\hline Spence et al., 2001 & LEDs (20 ms) & $200 \mathrm{~Hz}$ vibration (20 ms) & $27^{\circ}$ left and right & TOJs & $27^{\mathrm{a}}$ \\
\hline \multirow[t]{2}{*}{ Spence et al., 2003} & \multirow[t]{2}{*}{ LEDs (15 ms) } & \multirow[t]{2}{*}{$200 \mathrm{~Hz}$ vibration (15 ms) } & \multirow[t]{2}{*}{$23^{\circ}$ left and right } & \multirow[t]{2}{*}{ TOJs } & $10^{\mathrm{b}}$ (same location) \\
\hline & & & & & $24^{\mathrm{b}}$ (different location) \\
\hline Poliakoff et al., 2006 & LEDs (15 ms) & $200 \mathrm{~Hz}$ vibration (15 ms) & $15^{\circ}$ left and right & TOJs & $40^{c}$ \\
\hline Noel et al., 2015 & White ring on monitor (50 ms) & $50 \mathrm{~Hz}$ vibration $(50 \mathrm{~ms})$ & $\mathrm{V}: 0^{\circ}, \mathrm{T}: 35^{\circ}$ periphery & SJs & -73 \\
\hline $\begin{array}{l}\text { van der Burg et al., } \\
2015\end{array}$ & White ring on monitor (50 ms) & $50 \mathrm{~Hz}$ vibration $(50 \mathrm{~ms})$ & $\mathrm{V}: 0^{\circ}, \mathrm{T}: 35^{\circ}$ periphery & SJs & $-75^{\mathrm{d}}$ \\
\hline \multirow[t]{2}{*}{ Zhou (2016) ${ }^{\mathrm{e}}$} & \multirow[t]{2}{*}{$\begin{array}{l}\text { White flash on monitor (17 } \\
\text { ms) }\end{array}$} & \multirow[t]{2}{*}{ Tap (17 ms) } & \multirow[t]{2}{*}{$\mathrm{V}: 0^{\circ}, \mathrm{T}: 20^{\circ}$ below } & TOJs & -50 \\
\hline & & & & SJs & -28 \\
\hline \multirow[t]{2}{*}{ Machulla et al., 2016} & \multirow[t]{2}{*}{ LEDs (20 ms) } & \multirow[t]{2}{*}{$40 \mathrm{~Hz}$ vibration (20 ms) } & \multirow[t]{2}{*}{$0^{\circ}$} & TOJs & $46^{\mathrm{f}}$ \\
\hline & & & & SJs & $-10^{\mathrm{f}}$ \\
\hline
\end{tabular}

V: Vision; T: Touch; TOJs: temporal order judgments; SJs: simultaneity judgments.

${ }^{a}$ The value represents the mean of the conditions when the visual stimulus was presented on the left and the vibrotactile stimulus on the right, or vice versa, in Experiment 1A.

${ }^{\mathrm{b}}$ The values reported here come from the condition in which the participant's hands were uncrossed.

${ }^{c}$ The value comes from their Figure 2. There was no significant difference when the visual and vibrotactile stimuli were presented in the same or different locations.

${ }^{\mathrm{d}}$ The value represents the mean of the conditions when the previous trial was a tactile-leading or a visual-leading one, and there were no significant differences in these two conditions. The values were provided by the author.

${ }^{\mathrm{e}}$ The apparatus and stimuli were the same as in the present study.

${ }^{\mathrm{f}}$ The estimated value of the PSS was significantly different in the TOJ and SJ tasks; nevertheless, the PSS estimated using the SJ was not significantly different from $0 \mathrm{~ms}$ (i.e., physical simultaneity). 


\section{Acknowledgments}

This study was funded by James S. McDonnell Foundation and NSERC to DM, and Discovery grant from NSERC to DIS. YCC and CS were supported by the AHRC Rethinking the Senses grant (AH/L007053/1). We thank Sally Stafford, Brendan Stanley, Amentha Rajagobal, Shirley Zhang, Alicia Chhin, and Sogol Afshar for all of their help in data collection.

\section{Authors' Notes}

This study was presented at the European Conference of Visual Perception, 2015 (23-27 Aug, Liverpool, UK) with published abstract: Chen, Y.-C., Lewis, T. L., Shore, D. I., \& Maurer, D. (2015). The development of the perception of visuotactile simultaneity. Perception, 44(Sl), 341-342. 


\section{References}

Alcalá-Quintana, R., \& García-Pérez, M. A. (2013). Fitting model-based psychometric functions to simultaneity and temporal-order judgment data: MATLAB and R routines. Behavior Research Methods, 45, 972-998.

Azañón, E., \& Soto-Faraco, S. (2008). Changing reference frames during the encoding of tactile events. Current Biology, 18, 1044-1049.

Bergenheim, M., Johansson, H., Granlund, B., \& Pedersen, J. (1996). Experimental evidence for a sensory synchronization of sensory information to conscious experience. In S. R. Hameroff, A. W. Kaszniak, \& A. C. Scott (Eds.), Toward a science of consciousness: The first Tuscon discussions and debates (pp. 303-310). Cambridge, MA: MIT Press.

Brainard, D. H. (1997). The Psychophysics Toolbox. Spatial Vision, 10, 433-436.

Bremner, A. J., Holmes, N. P., \& Spence, C. (2012). The development of multisensory representations of the body and of the space around the body. In A. J. Bremner, D. J. Lewkowicz, \& C. Spence (Eds.), Multisensory development (pp. 113-136). Oxford, UK: Oxford University Press.

Bremner, A. J., \& Spence, C. (2017). The development of tactile perception. In J. Benson (Ed.), Advances in Child Development and Behaviour, 52, 227-268. San Diego, CA: Elsevier.

Burr, D., \& Gori, M. (2012). Multisensory integration develops late in humans. In M. M. Murray \& M. T. Wallace (Eds.), The neural bases of multisensory processes (pp. 345-362). Boca Raton, FL: CRC Press.

Chen, Y.-C., Lewis, T. L., Shore, D. I., \& Maurer, D. (2017). The development of the perception of audiovisual simultaneity. Current Biology, 27, 583-589.

Chen, Y.-C., Shore, D. I., Lewis, T. L., \& Maurer, D. (2016). The development of the perception of audiovisual simultaneity. Journal of Experimental Child Psychology, 146, 17-33.

Chen, Y. C., \& Spence, C. (2017). Assessing the role of the 'unity assumption'on multisensory integration: A review. Frontiers in Psychology, 8:445. doi: 10.3389/fpsyg.2017.00445,

Cowie, D., Sterling, S., \& Bremner, A. J. (2016). The development of multisensory body representation and awareness continues to 10 years of age: Evidence from the rubber hand illusion. Journal of Experimental Child Psychology, 142, 230-238.

Ellemberg, D., Lewis, T. L., Liu, C. H., \& Maurer, D. (1999). Development of spatial and temporal vision during childhood. Vision Research, 39, 2325-2333.

Ernst, M. O. (2008). Multisensory integration: A late bloomer. Current Biology, 18, R519-R521. 
Ernst, M. O., \& Banks, M. S. (2002). Humans integrate visual and haptic information in a statistically optimal fashion. Nature, 415, 429-433.

Filippetti, M. L., Johnson, M. H., Lloyd-Fox, S., Dragovic, D., \& Farroni, T. (2013). Body perception in newborns. Current Biology, 23, 2413-2416.

Filippetti, M. L., Lloyd-Fox, S., Longo, M. R., Farroni, T., \& Johnson, M. H. (2015). Neural mechanisms of body awareness in infants. Cerebral Cortex, 25, 3779-3787.

Fujisaki, W., \& Nishida, S. (2010). A common perceptual temporal limit of binding synchronous inputs across different sensory attributes and modalities. Proceedings of the Royal Society B, 277, 2281-2290.

García-Pérez, M. A., \& Alcalá-Quintana, R. (2012a). On the discrepant results in synchrony judgment and temporal-order judgment tasks: A quantitative model. Psychonomic Bulletin \& Review, 19, 820-846.

García-Pérez, M. A., \& Alcalá-Quintana, R. (2012b). Response errors explain the failure of independent-channels models of perception of temporal order. Frontiers in Psychology, 3:94.

Gori, M. (2015). Multisensory integration and calibration in children and adults with and without sensory and motor disabilities. Multisensory Research, 28, 71-99.

Gori, M., Del Viva, M., Sandini, G., \& Burr, D. C. (2008). Young children do not integrate visual and haptic form information. Current Biology, 18, 694-698.

Gori, M., Giuliana, L., Sandini, G., \& Burr, D. (2012). Visual size perception and haptic calibration during development. Developmental Science, 15, 854-862.

Gori, M., Sandini, G., Martinoli, C., \& Burr, D. (2010). Poor haptic orientation discrimination in nonsighted children may reflect disruption of cross-sensory calibration. Current Biology, 20, 223-225.

Gori, M., Sandini, G., Martinoli, C., \& Burr, D. (2014). Impairment of auditory spatial localization in congenitally blind human subjects. Brain, 137, 288-293.

Grabot, L., \& van Wassenhove, V. (2017). Time order as psychological bias. Psychological Science, 28, 670-678.

Hartcher-O’Brien, J., Gallace, A., Krings, B., Koppen, C., \& Spence, C. (2008). When vision 'extinguishes' touch in neurologically-normal people: Extending the Colavita visual dominance effect. Experimental Brain Research, 186, 643-658.

Hecht, D., \& Reiner, M. (2009). Sensory dominance in combinations of audio, visual and haptic stimuli. Experimental Brain Research, 193, 307-314.

Heed, T., \& Azañón, E. (2014). Using time to investigate space: A review of tactile temporal order judgments as a window onto spatial processing in touch. Frontiers in Psychology, 5:76. doi: 10.3389/fpsyg.2014.00076 
Hermelin, B., \& O'Connor, N. (1964). Effects of sensory input and sensory dominance on severely disturbed, autistic children and on subnormal controls. British Journal of Psychology, 55, 201206.

Jaśkowsky, P., \& Verleger, R. (2000). Attentional bias toward low-intensity stimuli: An explanation for the intensity dissociation between reaction time and temporal order judgment?

Consciousness and Cognition, 9, 435-456.

Klein, R. M. (1977). Attention and visual dominance: A chronometric analysis. Journal of Experimental Psychology: Human Perception and Performance, 3, 365-378.

Kleiner, M., Brainard, D., \& Pelli, D. (2007). What's new in Psychtoolbox-3? Perception, 36 (Sl), 14.

Lewkowicz, D. J., Leo, I., \& Simion, F. (2010). Intersensory perception at birth: newborns match nonhuman primate faces and voices. Infancy, 15, 46-60.

Love, S. A., Petrini, K., Cheng, A., \& Pollick, F. E. (2013). A psychophysical investigation of differences between synchrony and temporal order judgments. PLoS ONE, 8:e54798.

Macefield, G., Gandevia, S. C., \& Burke, D. (1989). Conduction velocities of muscle and cutaneous afferents in the upper and lower limbs of human subjects. Brain, 112, 1519-1532.

Machulla, T. K., Di Luca, M., \& Ernst, M. O. (2016). The consistency of crossmodal synchrony perception across the visual, auditory, and tactile senses. Journal of Experimental Psychology: Human Perception and Performance, 42, 1026-1038.

Maurer, D., Stager, C. L., \& Mondloch, C. J. (1999). Cross-modal transfer of shape is difficult to demonstrate in one-month-olds. Child Development, 70, 1047-1057.

McGurk, H., \& Power, R. P. (1980). Intermodal coordination in young children: Vision and touch. Developmental Psychology, 16, 679-680.

Meltzoff, A. N., \& Borton, R. W. (1979). Intermodal matching by human neonates. Nature, 282, 403-404.

Meredith, M. A., Nemitz, J. W., \& Stein, B. E. (1987). Determinants of multisensory integration in superior colliculus neurons. I. Temporal factors. Journal of Neuroscience, 7, 3215-3229.

Morrongiello, B. A., Fenwick, K. D., \& Chance, G. (1998). Crossmodal learning in newborn infants: Inferences about properties of auditory-visual events. Infant Behavior and Development, 21, $543-553$.

Ngo, M. K., \& Spence, C. (2010). Crossmodal facilitation of masked visual target identification. Attention, Perception, \& Psychophysics, 72, 1938-1947. 
Noel, J. P., Wallace, M. T., Orchard-Mills, E., Alais, D., \& van der Burg, E. (2015). True and perceived synchrony are preferentially associated with particular sensory pairings. Scientific Reports, 5:17467. doi: 10.1038/srep17467.

Pagel, B., Heed, T., \& Röder, B. (2009). Change of reference frame for tactile localization during child development. Developmental Science, 12, 929-937.

Pelli, D. G. (1997) .The VideoToolbox software for visual psychophysics: Transforming numbers into movies. Spatial Vision, 10, 437-442.

Peters, M. (1998). Description and validation of a flexible and broadly usable handedness questionnaire. Laterality, 3, 77-96.

Pihko, E., Nevalainen, P., Stephen, J., Okada, Y., \& Lauronen, L. (2009). Maturation of somatosensory cortical processing from birth to adulthood revealed by magnetoencephalography. Clinical Neurophysiology, 120, 1552-1561.

Poliakoff, E., Shore, D. I., Lowe, C., \& Spence, C. (2006). Visuotactile temporal order judgments in ageing. Neuroscience Letters, 396, 207-211.

Posner, M. I., Nissen, M. J., \& Klein, R. M. (1976). Visual dominance: An information-processing account of its origins and significance. Psychological Review, 83, 157-171.

Ridderinkhof, K. R., van der Molen, M. W., Band, G. P., \& Bashore, T. R. (1997). Sources of interference from irrelevant information: A developmental study. Journal of Experimental Child Psychology, 65, 315-341.

Röder, B., Pagel, B., \& Heed, T. (2013). The implicit use of spatial information develops later for crossmodal than for intramodal temporal processing. Cognition, 126, 301-306.

Rose, S. A., Gottfried, A. W., \& Bridger, W. H. (1981). Cross-modal transfer in 6-month-old infants. Developmental Psychology, 17, 661-669.

Rueda, M. R., Fan, J., McCandliss, B. D., Halparin, J. D., Gruber, D. B., Lercari, L. P., \& Posner, M. I. (2004). Development of attentional networks in childhood. Neuropsychologia, 42, 10291040 .

Sann, C., \& Streri, A. (2007). Perception of object shape and texture in human newborns: Evidence from cross-modal transfer tasks. Developmental Science, 10, 399-410.

Shore, D. I., Burack, J. A., Miller, D., Joseph, S., \& Enns, J. T. (2006). The development of change detection. Developmental Science, 9, 490-497.

Shore, D. I., Gray, K., Spry, E., \& Spence, C. (2005). Spatial modulation of tactile temporal-order judgments. Perception, 34, 1251-1262.

Shore, D. I., Spry, E., \& Spence, C. (2002). Confusing the mind by crossing the hands. Cognitive Brain Research, 14, 153-163.

Smith, W. F. (1933). The relative quickness of visual and auditory perception. Journal of Experimental Psychology, 16, 239-257. 
Spence, C., Baddeley, R., Zampini, M., James, R., \& Shore, D. I. (2003). Multisensory temporal order judgments: When two locations are better than one. Perception \& Psychophysics, 65, $318-328$.

Spence, C., Parise, C., \& Chen, Y.-C. (2012). The Colavita visual dominance effect. In M. M. Murray \& M. Wallace (Eds.), Frontiers in the neural bases of multisensory processes (pp. 529556). Boca Raton, FL: CRC Press.

Spence, C., Shore, D. I., \& Klein, R. M. (2001). Multisensory prior entry. Journal of Experimental Psychology: General, 130, 799-832.

Stein, B. E., \& Meredith, M. A. (1993). The merging of the senses. Cambridge, MA: The MIT Press.

Streri, A. (2012). Crossmodal interactions in the human newborn In A. J. Bremner, D. J. Lewkowicz, \& C. Spence (Eds.), Multisensory development (pp. 88-112). Oxford, UK: Oxford University Press.

Takahashi, C., Diedrichsen, J., \& Watt, S. J. (2009). Integration of vision and haptics during tool use. Journal of Vision, 9(6):3, 1-13. doi:10.1167/9.6.3.

van der Burg, E., Olivers, C. N., Bronkhorst, A. W., \& Theeuwes, J. (2009). Poke and pop: Tactilevisual synchrony increases visual saliency. Neuroscience letters, 450, 60-64.

van der Burg, E., Orchard-Mills, E., \& Alais, D. (2015). Rapid temporal recalibration is unique to audiovisual stimuli. Experimental Brain Research, 233, 53-59.

Virsu, V., Oksanen-Hennah, H., Vedenpää, A., Jaatinen, P., \& Lahti-Nuuttila, P. (2008).

Simultaneity learning in vision, audition, tactile sense and their cross-modal combinations. Experimental Brain Research, 186, 525-537.

Vroomen, J., \& Keetels, M. (2010). Perception of intersensory synchrony: a tutorial review. Attention, Perception, \& Psychophysics, 72, 871-884.

Warren, D. H., Welch, R. B., \& McCarthy, T. J. (1981). The role of visual-auditory 'compellingness' in the ventriloquism effect: Implications for transitivity among the spatial senses. Perception \& Psychophysics, 30, 557-564.

Welch, R. B., \& Warren, D. H. (1980). Immediate perceptual response to intersensory discrepancy. Psychological Bulletin, 88, 638-667.

Zampini, M., Shore, D. I., \& Spence, C. (2005). Audiovisual prior entry. Neuroscience Letters, 381, 217-222.

Zhou, Y. (2016). The temporal window of visuotactile tntegration. Unpublished Masters thesis, McMaster University.

Zmyj, N., Jank, J., Schütz-Bosbach, S., \& Daum, M. M. (2011). Detection of visual-tactile contingency in the first year after birth. Cognition, 120, 82-89. 


\section{Appendix A: The results when outliers in each age group were excluded.}

Table A1. Percentage of simultaneous responses in each age group, the results of one-way ANOVAs, and post-hoc tests (Dunnett) for the proportion of simultaneous responses at each SOA. Negative SOAs indicate the conditions where the tap was presented first, while positive SOAs indicate conditions where the flash was presented first.

\begin{tabular}{|c|c|c|c|c|c|c|c|c|c|}
\hline \multirow[b]{2}{*}{$\mathrm{SOA}(\mathrm{ms})$} & \multicolumn{5}{|c|}{ Age group } & \multirow[b]{2}{*}{$F(4,86)$} & \multirow[b]{2}{*}{$p$} & \multirow[b]{2}{*}{$\eta_{p}^{2}$} & \multirow{2}{*}{$\begin{array}{l}\text { Post-hoc tests } \\
(*: p<.05 ; * *: p<.01)\end{array}$} \\
\hline & $\begin{array}{c}7 \\
(\mathrm{~N}=18)\end{array}$ & $\begin{array}{c}9 \\
(\mathrm{~N}=18)\end{array}$ & $\begin{array}{c}11 \\
(\mathrm{~N}=18)\end{array}$ & $\begin{array}{c}13 \\
(\mathrm{~N}=18)\end{array}$ & $\begin{array}{l}\text { Adults } \\
(\mathrm{N}=19)\end{array}$ & & & & \\
\hline-1200 & 8.3 & 5.6 & 0.8 & 0.6 & 0 & 9.92 & $<.001$ & 0.32 & $7>$ Adults $* * ; 9>$ Adults $* *$ \\
\hline-800 & 17.2 & 5.0 & 0.6 & 1.7 & 1.6 & 16.16 & $<.001$ & 0.43 & $7>$ Adults $* *$ \\
\hline-400 & 42.2 & 22.5 & 8.1 & 10.3 & 17.9 & 7.37 & $<.001$ & 0.26 & $7>$ Adults $* *$ \\
\hline-300 & 58.3 & 47.8 & 28.1 & 21.4 & 31.1 & 6.70 & $<.001$ & 0.24 & $7>$ Adults $* *$ \\
\hline-200 & 72.2 & 72.2 & 63.1 & 63.3 & 58.7 & 1.03 & $=.40$ & 0.05 & \\
\hline-100 & 81.9 & 88.3 & 87.8 & 90.6 & 91.6 & 1.70 & $=.16$ & 0.07 & \\
\hline 0 & 82.5 & 88.6 & 95.3 & 94.2 & 98.4 & 9.72 & $<.001$ & 0.31 & $7<$ Adults $* * ; 9<$ Adults $* *$ \\
\hline 100 & 81.9 & 76.4 & 75.6 & 74.7 & 73.2 & 0.43 & $=.78$ & 0.02 & \\
\hline 200 & 65.0 & 60.8 & 38.6 & 33.6 & 35.0 & 5.23 & $<.005$ & 0.20 & $7>$ Adults $* * ; 9>$ Adults $*$ \\
\hline 300 & 41.7 & 30.8 & 17.2 & 17.5 & 12.9 & 5.02 & $<.005$ & 0.19 & $7>$ Adults $* *$ \\
\hline 400 & 37.2 & 17.8 & 4.7 & 11.7 & 8.7 & 8.41 & $<.001$ & 0.28 & $7>$ Adults $* *$ \\
\hline 800 & 17.5 & 6.1 & 1.1 & 3.1 & 0.8 & 15.59 & $<.001$ & 0.42 & $7>$ Adults $* *$ \\
\hline 1200 & 8.1 & 6.4 & 0.8 & 1.4 & 0.8 & 9.79 & $<.001$ & 0.31 & $7>$ Adults $* * ; 9>$ Adults $* *$ \\
\hline
\end{tabular}


Table A2. The mean (in bold) and SE (in parentheses) of estimated parameters of the simultaneity judgment task for each age group.

\begin{tabular}{|c|c|c|c|c|c|c|c|c|c|}
\hline \multirow[b]{2}{*}{ Parameter } & \multicolumn{5}{|c|}{ Age group } & \multirow[b]{2}{*}{$F(4,86)$} & \multirow[b]{2}{*}{$p$} & \multirow[b]{2}{*}{$\eta_{p}^{2}$} & \multirow{2}{*}{$\begin{array}{l}\text { Post-hoc tests } \\
(*: p<.05 ; * *: p<.01)\end{array}$} \\
\hline & $\begin{array}{c}7 \\
(\mathrm{~N}=18) \\
\end{array}$ & $\begin{array}{c}9 \\
(\mathrm{~N}=18)\end{array}$ & $\begin{array}{c}11 \\
(\mathrm{~N}=18)\end{array}$ & $\begin{array}{c}13 \\
(\mathrm{~N}=18)\end{array}$ & $\begin{array}{l}\text { Adults } \\
(\mathrm{N}=19)\end{array}$ & & & & \\
\hline$\delta$ & $\begin{array}{l}391.6 \\
(44.6)\end{array}$ & $\begin{array}{l}279.2 \\
(15.5)\end{array}$ & $\begin{array}{l}\mathbf{2 1 8 . 0} \\
(18.4)\end{array}$ & $\begin{array}{l}225.9 \\
(22.1)\end{array}$ & $\begin{array}{l}225.2 \\
(25.4)\end{array}$ & 7.23 & $<.001$ & 0.25 & $7>$ Adults $* *$ \\
\hline PSS & $\begin{array}{l}\mathbf{- 5 0 . 0} \\
(18.2)\end{array}$ & $\begin{array}{l}-\mathbf{3 7 . 7} \\
(8.6)\end{array}$ & $\begin{array}{r}-23.0 \\
(4.4)\end{array}$ & $\begin{array}{l}\mathbf{- 2 0 . 6} \\
(10.4)\end{array}$ & $\begin{array}{l}-47.0 \\
(11.9)\end{array}$ & 1.34 & $=.26$ & 0.06 & \\
\hline$\lambda \mathrm{T}$ & $\begin{array}{c}\mathbf{0 . 0 5} \\
(0.02)\end{array}$ & $\begin{array}{c}\mathbf{0 . 1 1} \\
(0.05)\end{array}$ & $\begin{array}{c}\mathbf{0 . 0 5} \\
(0.02)\end{array}$ & $\begin{array}{c}\mathbf{0 . 1 0} \\
(0.04)\end{array}$ & $\begin{array}{c}\mathbf{0 . 2 5} \\
(0.07)\end{array}$ & 3.20 & $<.05$ & 0.13 & $7<$ Adults $* ; 11<$ Adults $*$ \\
\hline$\lambda \mathrm{V}$ & $\begin{array}{c}\mathbf{0 . 2 0} \\
(0.08)\end{array}$ & $\begin{array}{c}\mathbf{0 . 0 8} \\
(0.06)\end{array}$ & $\begin{array}{c}\mathbf{0 . 2 2} \\
(0.08)\end{array}$ & $\begin{array}{c}\mathbf{0 . 1 5} \\
(0.07)\end{array}$ & $\begin{array}{c}\mathbf{0 . 1 5} \\
(0.07)\end{array}$ & 0.62 & $=.65$ & 0.03 & \\
\hline $\mathrm{T}$ & $\begin{array}{c}71.0 \\
(41.4)\end{array}$ & $\begin{array}{c}42.0 \\
(24.6)\end{array}$ & $\begin{array}{c}11.3 \\
(12.0)\end{array}$ & $\begin{array}{c}9.6 \\
(24.2)\end{array}$ & $\begin{array}{c}\mathbf{6 5 . 3} \\
(22.8)\end{array}$ & 1.18 & $=.33$ & 0.05 & \\
\hline$\varepsilon \mathrm{TF}$ & $\begin{array}{c}\mathbf{0 . 0 8} \\
(0.02)\end{array}$ & $\begin{array}{c}\mathbf{0 . 0 4} \\
(0.01)\end{array}$ & $\begin{array}{c}\mathbf{0 . 0 1} \\
(0.003)\end{array}$ & $\begin{array}{c}\mathbf{0 . 0 1} \\
(0.003)\end{array}$ & $\begin{array}{c}\mathbf{0 . 0 1} \\
(0.003)\end{array}$ & 11.65 & $<.001$ & 0.35 & $7>$ Adults $* * ; 9>$ Adults * \\
\hline$\varepsilon S$ & $\begin{array}{c}\mathbf{0 . 1 0} \\
(0.03)\end{array}$ & $\begin{array}{c}\mathbf{0 . 0 9} \\
(0.02)\end{array}$ & $\begin{array}{c}\mathbf{0 . 0 3} \\
(0.01)\end{array}$ & $\begin{array}{c}\mathbf{0 . 0 3} \\
(0.01)\end{array}$ & $\begin{array}{c}\mathbf{0 . 0 1} \\
(0.01)\end{array}$ & 4.56 & $<.005$ & 0.18 & $7>$ Adults $* * ; 9>$ Adults $*$ \\
\hline$\varepsilon V F$ & $\begin{array}{c}\mathbf{0 . 0 9} \\
(0.02)\end{array}$ & $\begin{array}{c}\mathbf{0 . 0 6} \\
(0.01)\end{array}$ & $\begin{array}{c}\mathbf{0 . 0 1} \\
(0.003)\end{array}$ & $\begin{array}{c}\mathbf{0 . 0 2} \\
(0.01)\end{array}$ & $\begin{array}{c}\mathbf{0 . 0 1} \\
(0.003)\end{array}$ & 10.92 & $<.001$ & 0.34 & $7>$ Adults $* * ; 9>$ Adults $* *$ \\
\hline
\end{tabular}

$\delta$ : resolution (threshold of simultaneity perception); PSS: point of subjective simultaneity; $\lambda \mathrm{T}$ : processing variability of tactile stimulus; $\lambda \mathrm{V}$ : processing variability of visual stimulus; $\tau$ : processing time difference between tactile and visual stimulus $(\tau \mathrm{T}-\tau \mathrm{V})$; $\varepsilon \mathrm{TF}$ : response errors in the tactile-leading trials; $\varepsilon S$ : response errors in the simultaneous trials; $\varepsilon \mathrm{VF}$ : response errors in the visual-leading trials. 